\title{
Double Steal Syndrome: Two Case Presentations
}

Ashley D Willoughby ${ }^{1 *}$, Dwight C Kellicut ${ }^{1}$, Brian H Ching DO ${ }^{2}$, Anthony Katras ${ }^{1}$, Michelle Shimabukuro ${ }^{1}$ and Farhan S Ayubi ${ }^{1}$

${ }^{1}$ Department of Vascular Surgery, Tripler Army Medical Center, Honolulu, HI, USA

${ }^{2}$ Department of Interventional Radiology, Tripler Army Medical Center, Honolulu, HI, USA

\begin{abstract}
Double steal syndrome is a phenomenon that has been minimally described in the literature and here we present two cases. The first case presented with symptoms and early evidence of reversal of flow on carotid duplex in the right proximal internal carotid artery with significant innominate stenosis. The second case was an asymptomatic patient with clear retrograde flow observed in the right proximal internal carotid artery with innominate stenosis. Both patients were also found to have reversal of flow in the vertebral artery of the ipsilateral side. Intervention consisted of stent placement at the proximal origin of the innominate artery. Both patients remained on clopidogrel according to post-procedure instructionsand returned to the clinic within the first week for follow up carotid duplex demonstrating decreased innominate velocity with antegrade right internal carotid and vertebral artery flow.
\end{abstract}

Keywords: Innominate stenosis; Internal carotid artery; Vertebral artery; Carotid duplex; Endovascular intervention; Reversal of flow

Abbreviations: PCI: Percutaneous Intervention; SBP: Systolic Blood Pressure; ICA: Internal Carotid Artery; CTA: Computed Topography Angiogram; Fr: French; PTA: Percutaneous Transluminal Angioplasty; CCA: Common Carotid Artery; TIA: Transient Ischemic Attack

\section{Introduction}

Atherosclerotic disease of the branches from the aortic arch may cause high grade stenosis or may occlude the arch branch vessels. Subclavian steal syndrome was first described in 1961 and is a well described phenomenon of reversal of flow in the ipsilateral vertebral artery with stenosis or occlusion of the subclavian artery or innominate artery [1]. This syndrome manifests with signs and symptoms of vertebrobasilar insufficiency. Occlusive disease of the proximal innominate trunk is relatively rare when compared to the carotid and subclavian arteries. However, stenosis of the innominateartery will decrease the inflow to the right upper extremity as well as to the right carotid which has potential to result in ipsilateral upper extremity

\begin{tabular}{|c|c|c|c|c|c|}
\hline & $\begin{array}{c}\text { Innominate } \\
\text { Velocity } \\
\text { (cm/s) }\end{array}$ & $\begin{array}{c}\text { Innominate } \\
\text { Stenosis } \\
\text { (\%) }\end{array}$ & $\begin{array}{c}\text { RICA } \\
\text { Stenosis/ }\end{array}$ & $\begin{array}{c}\text { LICA } \\
\text { Stenosis/ }\end{array}$ & $\begin{array}{c}\text { Vertebral } \\
\text { Flow }\end{array}$ \\
\hline $\begin{array}{c}\text { Initial Carotid } \\
\text { Duplex }\end{array}$ & 832 & $>50 \%$ & $\begin{array}{c}<30 \% \\
\text { To \& fro }\end{array}$ & $\begin{array}{c}30-49 \% \\
\text { antegrade }\end{array}$ & $\begin{array}{c}\text { R: retrograde } \\
\text { L: antegrade }\end{array}$ \\
\hline $\begin{array}{c}\text { Post- } \\
\text { Intervention }\end{array}$ & 277 & $<50 \%$ & $\begin{array}{c}<30 \% \\
\text { antegrade }\end{array}$ & $\begin{array}{c}<30 \% \\
\text { antegrade }\end{array}$ & $\begin{array}{c}\text { R: antegrade } \\
\text { L: antegrade }\end{array}$ \\
\hline
\end{tabular}

Table 1: Carotid duplex results of Pre- and Post-Intervention for Innominate Stenosis.

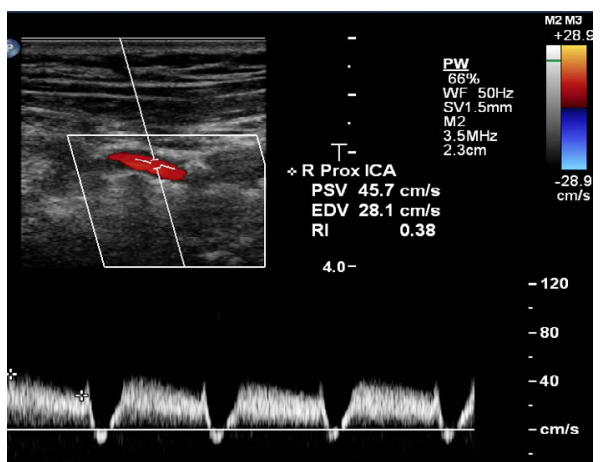

Figure 1a: (Case 1) Pre-procedure carotid duplex demonstrating To \& Fro waveform of the right ICA. symptoms and cerebrovascular insufficiency [2]. Many collateral supplies may develop to prevent the onset of these symptoms and the contralateral carotid and vertebral artery will continue to supply the circle of Willis preventing ischemia [2]. A phenomenon that has been minimally described in the literature is that of a "double steal syndrome." This syndrome is characterized by stenosis of the innominate artery, most commonly a proximal stenosis, resulting in reversal of flow in the ipsilateral vertebral and carotid artery. Here we present two cases of innominate stenosis. One patient was symptomatic with early evidence for reversal of flow demonstrated on carotid duplex with real-time imaging and point-spectral analysis at the site of maximal velocity in the vessel [3]. The second case was asymptomatic with clear retrograde flow observed in the internal carotid artery.

\section{First case presentation}

A 64 year old obese male with past medical history significant fortobacco use, hypertension and hyperlipidemia. The patient had a history of atherosclerosis of bilateral common iliac arteries and distal aorta both requiring angioplasty; as well as a cardiac catheterization with PCI.He was evaluated by cardiology for unstable angina pectoris 6 months prior to presentation. He was found to have coronary artery disease and was managed medically. The cardiologist noted a difference in SBP with left greater than right by $20-60 \mathrm{mmHg}$ and was referred to the vascular surgery clinic.

He presented to the vascular surgery clinic with symptoms of weakness and pain in his right shoulder with use and pre-syncope with full head extension. Initial carotid duplex results are demonstrated in Table 1. These findings correlated with a proximal stenosis of the innominate artery resulting in progressive early systolic deceleration waveforms. This pattern is also known as the "To\&Fro" pattern resulting from increasing degree of stenosis in the respective vessel (Figure 1A). Flow is retrograde in systole, but returns to an antegrade direction

*Corresponding author: Ashley D. Willoughby, Department of Surgery/ General Surgery, Tripler Army Medical Center, 1 Jarrett White Road, Tripler AMC, HI 96859, USA, Tel: (808) 433-3479; Fax: (808) 433-6152; E-mail: ashley.d.willoughby.mil@mail.mil

Received June 02, 2014; Accepted July 07, 2014; Published July 09, 2014

Citation: Willoughby AD, Kellicut DC, DO BHC, Katras A, Shimabukuro M, et al (2014) Double Steal Syndrome: Two Case Presentations. J Vasc Med Surg 2: 143 doi: 10.4172/2329-6925.1000143

Copyright: (C) 2014 Willoughby AD, et al. This is an open-access article distributed under the terms of the Creative Commons Attribution License, which permits unrestricted use, distribution, and reproduction in any medium, provided the original author and source are credited. 


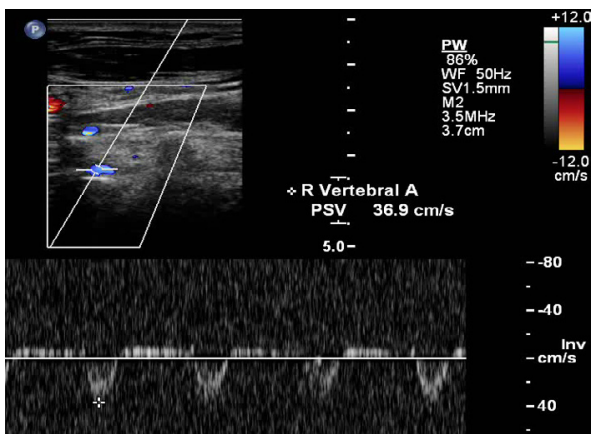

Figure 1b: (Case1) Pre-procedure carotid duplex demonstrating retrograde flow in right vertebral artery.

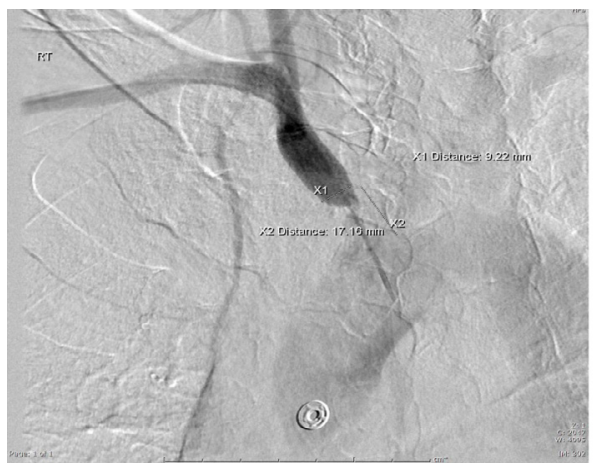

Figure 2a: (Case 1) Pre-procedure angiogram demonstrating innominate artery stenosis.

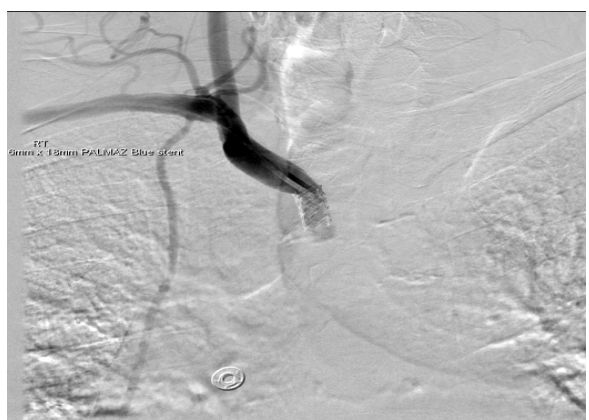

Figure 2b: (Case 1) Post-procedure angiogram with stent deployment across innominate artery stenosis via retrograde approach.

in diastole.This waveform precede retrograde flow of the right ICA. Complete reversal of flow was observed in the right vertebral artery (Figure 1B).

He underwent a CTA demonstrating $>90 \%$ stenosis of the proximal $1.7 \mathrm{~cm}$ of the innominate artery. Six months after his cardiac catheterization, he underwent endovascular treatment of the innominate artery (Figure 2A and 2B). Digital subtraction angiography of the right subclavian artery revealed a greater than $90 \%$ stenosis of the proximal innominate artery as noted on the CTA. The right brachial artery was chosen as the access vessel due to the ease of crossing the lesion from a retrograde approach rather than an antegrade approach since the lesion was flush with the aortic arch. A $6 \mathrm{~mm} \times 18 \mathrm{~mm}$ bare metal balloon expandable stent was deployed across the origin of the innominate artery over an exchange length 0.035 " wire. The stent diameter was less than the diameter of the target vessel to minimize the crossing profile of the stent in order to reduce the risk of distal embolization of atherosclerotic debris. An $8 \mathrm{~mm} \times 40 \mathrm{~mm}$ compliant PTA balloon was used to expand the stent to profile with significant improvement of flow demonstrated in the innominate artery. Given the high hoop strength known to be associated with balloon expandable stents, extreme caution was used not to over dilate the lesion. There were no neurologic or other complications.

One week after intervention, a repeat carotid duplex (Table 1) demonstrated both the right and left ICA with antegrade flow (Figure $3 \mathrm{~A}$ ), as well as both vertebral arteries with antegrade flow (Figure 3B). The patient was prescribed clopidogrel for 90 days post-procedure and aspirin indefinitely. A repeat carotid duplex study was scheduled in one year.

\section{Second case presentation}

A 72 year old female was referred to our clinic with a past medical history significant for ischemic related dementia, diabetes type 2 on insulin, hyperlipidemia, congestive heart failure, breast and colon

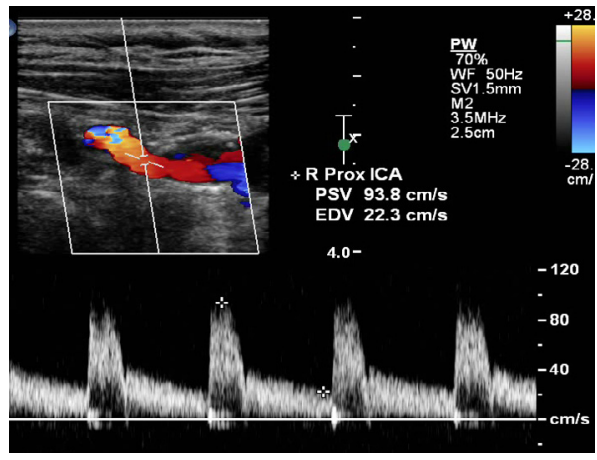

Figure 3a: (Case 1) Post-procedure carotid duplex demonstrating antegrade flow in the right ICA.

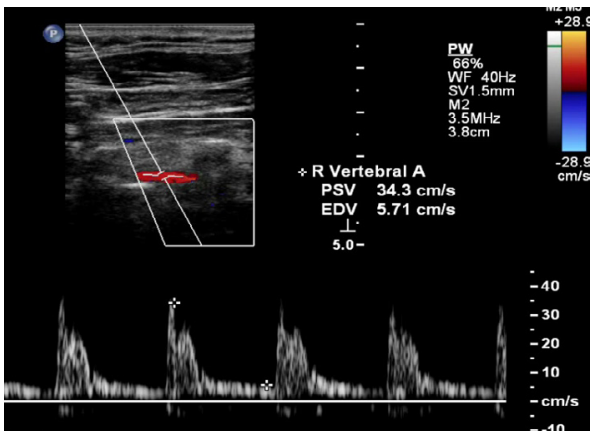

Figure 3b: (Case 1) Post-procedure carotid duplex demonstrating antegrade flow in the right vertebral artery.

\begin{tabular}{|c|c|c|c|c|c|}
\hline & $\begin{array}{c}\text { Innominate } \\
\text { Velocity } \\
\text { (cm/s) }\end{array}$ & $\begin{array}{c}\text { Innominate } \\
\text { Stenosis } \\
\mathbf{( \% )}\end{array}$ & $\begin{array}{c}\text { RICA } \\
\text { Stenosis/ }\end{array}$ & $\begin{array}{c}\text { LICA } \\
\text { Stenosis/ }\end{array}$ & $\begin{array}{c}\text { Vertebral } \\
\text { Flow }\end{array}$ \\
\hline $\begin{array}{c}\text { Initial Carotid } \\
\text { Duplex }\end{array}$ & 700 & $>50 \%$ & $\begin{array}{c}<30 \% \\
\text { retrograde }\end{array}$ & $\begin{array}{c}<30 \% \\
\text { antegrade }\end{array}$ & $\begin{array}{c}\text { R: retrograde } \\
\text { L: antegrade }\end{array}$ \\
\hline $\begin{array}{c}\text { Post- } \\
\text { Intervention }\end{array}$ & 349 & $\begin{array}{c}20-49 \% \\
\text { distal }\end{array}$ & $\begin{array}{c}<30 \% \\
\text { antegrade }\end{array}$ & $\begin{array}{c}<30 \% \\
\text { antegrade }\end{array}$ & $\begin{array}{c}\text { R: antegrade } \\
\text { L: antegrade }\end{array}$ \\
\hline
\end{tabular}

Table 2: Post-intervention Carotid duplex results of Pre- and Post-Intervention for innominate stenosis. 
cancer. The patient had no known history of cardiovascular or peripheral vascular disease. She had a history of transient ischemic attacks with the most recent 2 months prior to presentation. She received a carotid duplex at an outside facility demonstrating loss of normal waveforms in the right common carotid artery (CCA) with reversal of flow at the end of diastole and significant stenosis.

She denied symptoms at her initial visit; however an accompanying family member noted confusion and difficulty with ambulation. Initial carotid duplex (Table 2) demonstrated retrograde flow in the proximal right ICA, and antegrade flow in left ICA (Figure 4A). The right vertebral artery had retrograde flow (Figure 4B). A CTA demonstrated $70 \%$ stenosis at the proximal innominate artery.

The patient underwent endovascular treatment of the innominate stenosis (Figure 5A and 5B). The right common femoral artery was chosen as the access site. The right common femoral access site was chosen because the lesion was not flush with the aortic arch and the success of crossing the lesion of the arch seemed reasonable. An arch aortogram demonstrated high-grade (greater than $80 \%$ ) stenosis at the origin of the innominate artery with poststenotic dilatation. The origin of the proximal innominate artery diameter measured $5 \mathrm{~mm}$. Access across the innominate stenosis was performed by means of a 5 Fr selective catheter and 0.035 " guide wire. A Rosen wire was then placed in the mid common carotid artery. The $5 \mathrm{Fr}$ femoral sheath was then exchanged for a $90 \mathrm{~cm}$ shuttle sheath. A $5 \mathrm{~mm} \times 22 \mathrm{~mm}$ balloon expandable covered stentwas positioned across the stenosis and deployed.The stent was gentlyflared partially into the aortic arch using a $7 \times 20 \mathrm{~mm}$ PTA balloon to prevent restenosis. The same reasoning of choosing a balloon expandable stent as well as undersizing the balloon diameter was used as in the first case. The post stent deployment and

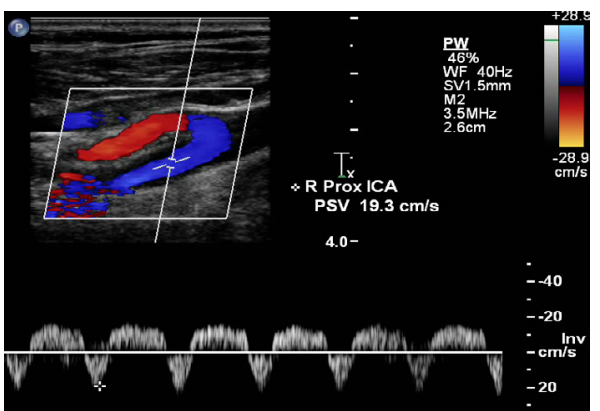

Figure 4a: (Case 2) Pre-procedure carotid duplex demonstrating complete reversal of flow in proximal right ICA.

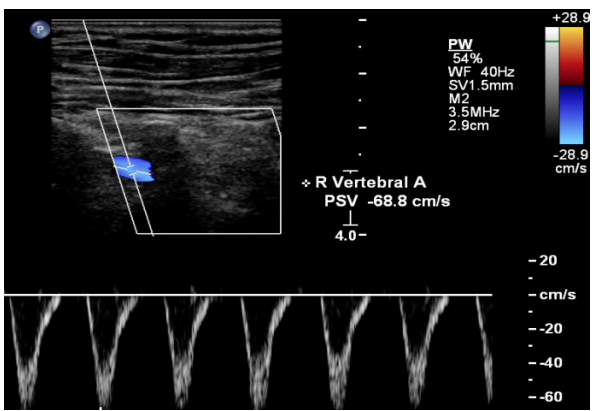

Figure 4b: (Case 2) Pre-procedure carotid duplex demonstrating retrograde flow in the right vertebral artery.

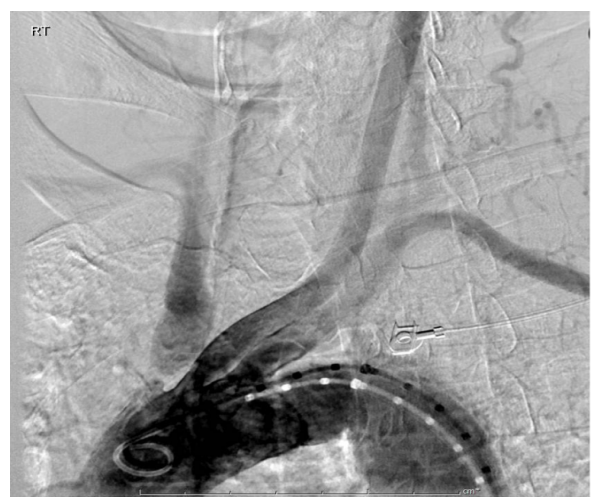

Figure 5a: (Case 2) Pre-procedure angiogram demonstrating innominate artery lesion.

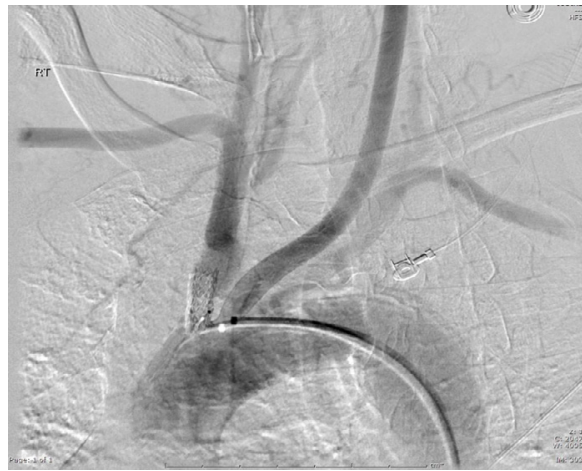

Figure 5b: (Case 2) Post-procedure angiogram with stent deployment across deployed across innominate artery stenosis.

PTA angiograms demonstrated improvement in angiographic flow. There were no neurologic or other complications.

Post-intervention carotid duplex (Table 2) demonstrated both vertebral and carotid arteries with antegrade flow (Figure 6A and 6B). The patient was prescribed clopidogrel for 30 days post procedure and aspirin indefinitely. A repeat carotid duplex was scheduled 3 months post procedure.

\section{Discussion}

We have presented two cases of innominate stenosis with consequent ipsilateral vertebral artery retrograde flow also known as double steal syndrome as documented in the literature. A retrograde vertebral artery waveform should alert the evaluator to look for an additional stenosis from the aortic arch vessels. A peak systolic velocity of greater than twice the normal value is likely to be found in this scenario [4].

Our first case presentation demonstrated signs and symptoms of decreased subclavian inflow with pain in his right shoulder during use.His "To \& Fro" pattern reflected a gradient differential in brachial pressures on exam (Figure 1A). In the second case presentation, a female with questionable symptoms presented with complete reversal of proximal right ICA flow. The difference in the presentation and ultrasound findings between these two patients further demonstrates patients with severe carotiddisease and significant imaging findings may remain clinically asymptomatic due to vast collateralization. The atherosclerotic lesions form progressively while allowing collateral 


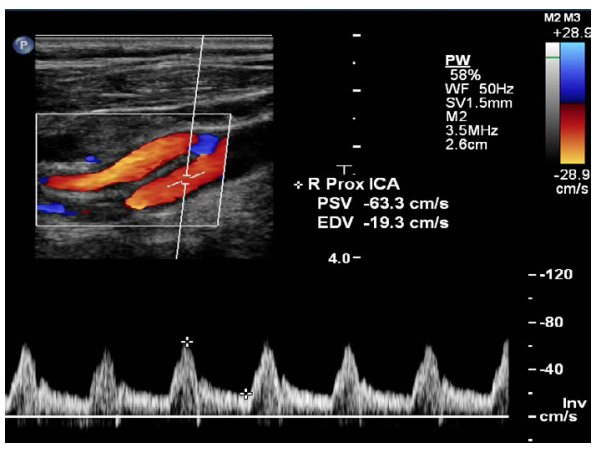

Figure 6a: (Case 2) Post-procedure carotid duplex demonstrating antegrade flow in the proximal right ICA.

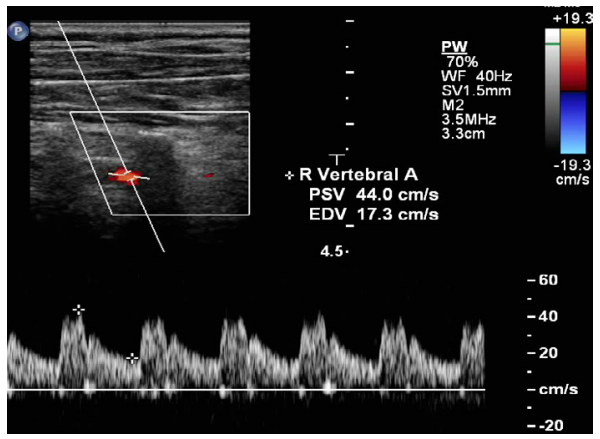

Figure 6b: (Case 2) Post-procedure carotid duplex demonstrating antegrade flow in the right vertebral artery.

arterial supply to develop that aids in supply to the circle of Willis and the right upper extremity [2].

Surgical techniques include anatomic and extra-anatomic bypass. Anatomic bypass such as an aortoinnominate patient remains the open surgical option with the best patency rates [5]. The extra-anatomic bypass options (carotid to carotid bypass, axillary to axillary bypass) are more appropriate for patients with symptomatic disease who are not candidates for a median sternotomy due to other comorbidities.

Both of our patients were felt not to be candidates for an open repair secondary to their comorbidities. Another reason we chose an endovascular approach is because the short term and long term results of endovascular intervention for treatment of innominate stenosis are approaching open repair patency rates. Results of endovascular intervention for innominate stenosis from a large series is $94 \%$ for oneyear patency rate and $89 \%$ for 5 year patency rate for combined stenotic and occlusive disease [6].

The innominate artery may be approached via a transfemoral route or from a brachial approach. Successful crossing of flush occlusions or high grade lesions at the origin of the aortic arch is more likely with a brachial approach over a transfemoral route [7]. A transfemoral approach may be more favorable if the patient is a female as in the second case, due to the higher rate of brachial access site complications in females, to include brachial artery thrombosis [8].
Most innominate interventions from a transfemoral route do not require the usage of cerebral protection devices [7]. Primary stent placement without having to predilate a lesion traps embolic prone plaques [9]. Lesion of the proximal aortic arch branch vessels benefit from balloon expandable stents because they ensure accuracy of placement location [10]. Whether a covered or bare metal balloon expandable stent is utilized, there is a paucity of data to suggest superiority of one over the other at this time for occlusive innominate artery disease [7].

\section{Conclusion}

Patients with retrograde flow visualized in the internal carotid artery on carotid duplex should be further evaluated for aortic arch vessel disease. We do not have long term results from the endovascular approach in the above case presentations; however their procedures were uncomplicated and are currently doing well and remain asymptomatic.

\section{References}

1. van der Steen A, Geervliet JP (1979) Collateral circulation and stealmechanisms in innominate and subclavian artery obstruction. Clin Neurol Neurosurg 81: 194-198.

2. Filis K, Toufektzian L, Sigala F, Kardoulas D, Kotzadimitriou A et al. (2008) Right subclavian double steal syndrome: a case report. J Med Case Rep 2: 392.

3. Middleton WD, Foley WD, Lawson TL (1988) Color-flow Doppler imaging of carotid artery abnormalities. AJR Am J Roentgenol 150: 419-425.

4. Rutherford Robert B (2010) Arterial Duplex Scanning. Rutherford (7thedn) Vascular Surgery. Elsevier Saunders, Philadelphia.

5. Francis C, Ward A, Cormier JM, Laurian C (1989) Long-tern results of aortoinnominate and aortocarotid polytetrafluoroethylene bypass grafting for atherosclerotic lesions. J Vasc Surg 10: 135-142.

6. De Vries JP, Jager LC, Van den Berg JC, Overtoom TT, Ackerstaff RG, et al. (2005) Durability of percutaneous transluminal angioplasty for obstructive lesions of proximal subclavian artery: long-term results. J Vasc Surg 41: 19-23.

7. Clair Daniel G (2010) Brachiocephalic Artery Disease: Endovascular Treatment Rutherford (7thedn) Vascular Surgery. Elsevier Saunders, Philadelphia.

8. Armstrong PJ, Han DC, Baxter JA, Elmore JR, Franklin DP (2003) Complication rates of percutaneous brachial artery access in peripheral vascular angiography. Ann Vasc Surg 17: 107-110.

9. Schneider Peter (2009) Endovascular Skill: Guidewire and Catheter Skills for Endovascular Surgery. (3rdedn), Informa Health Care, New York.

10. Hodgson, Kim J, Hood, Douglas (2010) Endovascular Therapy. Rutherford 7th Edition Vascular Surgery. Elsevier Saunders, Philadelphia. 